\title{
The Outcomes of Manipulation or Mobilization Therapy Compared with Physical Therapy or Exercise for Neck Pain: A Systematic Review
}

\author{
Josh Schroeder ${ }^{1}$ Leon Kaplan ${ }^{2}$ Dena J. Fischer ${ }^{3}$ Andrea C. Skelly ${ }^{3}$
}

${ }^{1}$ Department of Spine Surgery, The Hospital for Special Surgery, New York, New York, United States

2 Department of Orthopedic Surgery, Spine Unit, Hadassah Hebrew University Medical Center, Jerusalem, Israel

${ }^{3}$ Spectrum Research, Inc., Tacoma, Washington, United States

Evid Based Spine Care J 2013;4:30-41.

\begin{abstract}
Address for correspondence Josh Schroeder, MD, The Hospital for Special Surgery, 535 East 70th Street, New York, NY 10021, United States (e-mail: Schroeder.josh@gmail.com).
\end{abstract}

\begin{abstract}
Keywords

- neck pain

- spinal manipulation

- physical therapy

- exercise

- mobilization therapy
\end{abstract}

Study Design Systematic review.

Study Rationale Neck pain is a prevalent condition. Spinal manipulation and mobilization procedures are becoming an accepted treatment for neck pain. However, data on the effectiveness of these treatments have not been summarized.

Objective To compare manipulation or mobilization of the cervical spine to physical therapy or exercise for symptom improvement in patients with neck pain.

Methods A systematic review of the literature was performed using PubMed, the National Guideline Clearinghouse Database, and bibliographies of key articles, which compared spinal manipulation or mobilization therapy with physical therapy or exercise in patients with neck pain. Articles were included based on predetermined criteria and were appraised using a predefined quality rating scheme.

Results From 197 citations, 7 articles met all inclusion and exclusion criteria. There were no differences in pain improvement when comparing spinal manipulation to exercise, and there were inconsistent reports of pain improvement in subjects who underwent mobilization therapy versus physical therapy. No disability improvement was reported between treatment groups in studies of acute or chronic neck pain patients. No functional improvement was found with manipulation therapy compared with exercise treatment or mobilization therapy compared with physical therapy groups in patients with acute pain. In chronic neck pain subjects who underwent spinal manipulation therapy compared to exercise treatment, results for short-term functional improvement were inconsistent.

Conclusion The data available suggest that there are minimal short- and long-term treatment differences in pain, disability, patient-rated treatment improvement, treatment satisfaction, health status, or functional improvement when comparing manipulation or mobilization therapy to physical therapy or exercise in patients with neck pain. This systematic review is limited by the variability of treatment interventions and lack of standardized outcomes to assess treatment benefit. received

October 21, 2012

accepted

December 5, 2012 (c) 2013 Georg Thieme Verlag KG

Stuttgart · New York
DOI http://dx.doi.org/ $10.1055 / \mathrm{s}-0033-1341605$. ISSN 1663-7976. 


\section{Study Rationale and Context}

Neck pain is a prevalent condition; more than $66 \%$ of the population will suffer from neck pain in one's life span. ${ }^{1}$ It is commonly caused by trauma, disk degeneration, disk herniation, or strains of the neck muscles. Initial care for neck pain consists of rest, physical medicine (heat/ice therapy), and pharmacotherapy. However, when conservative measures fail, patients are referred for physical intervention to alleviate a patient's neck pain.

Alternative methods of treatment have become popular in mainstream medical practice, leading to numerous types of treatment for neck pain. Spinal manipulation and mobilization procedures are becoming an accepted therapy for cervical pain. In fact, in many countries, patients are reimbursed for chiropractic care. There is data supporting and also discouraging the use of such treatments; however, data on the effectiveness of these treatments have not been summarized.

\section{Objectives}

To compare manipulation or mobilization of the cervical spine to physical therapy, physiotherapy, or exercise for symptom improvement in patients with neck pain.

\section{Materials and Methods}

Study Design: Systematic review.

Search: PubMed and National Guideline Clearinghouse Databases; bibliographies of key articles.

Dates Searched: 1950 to August 2012.

Inclusion Criteria: Patients with neck pain. Studies explicitly designed to compare manipulation (chiropractic therapy) or mobilization (manual therapy) of the cervical spine to physical therapy or exercise for symptom improvement in patients with neck pain. Studies were considered if comparison of manipulation or mobilization to physical therapy, physiotherapy, or exercise in patients with neck pain was described in the title and/or abstract.

Exclusion Criteria: Cervical radiculopathy, spinal stenosis, myelopathic conditions, postsurgical pain, disk herniation, history of cervical vertebral fractures or spinal tumor, headache etiology of neck pain, spinal manipulation directed at the thoracic spine only (i.e., thoracic thrust manipulation), multimodal therapy, acupuncture, electrical stimulation, injections, surgical correction, massage, behavioral therapy, no treatment, studies with less than 10 subjects, and low quality studies (LoE III or lower).

Interventions: Cervical spinal manipulation (chiropractic therapy), cervical spinal mobilization (manual therapy).

Comparators: Physical therapy, exercise, Feldenkrais method, home exercises/mobilization, counseling/education, or pharmacotherapy if associated with physical therapy or exercise.

Outcomes: Pain reduction, decreased disability, symptomfree time, time/procedure length until improvement, improved quality of life, complications of treatment, and cost of treatment.

Analysis: Descriptive statistics, statistics, and effect estimates as reported by authors.

Overall Strength of Evidence: Risk of bias for individual studies was based on using criteria set by The Journal of Bone and Joint Surgery, ${ }^{2}$ modified to delineate criteria associated with methodological quality and risk of bias based on recommendations from the Agency for Healthcare Research and Quality. ${ }^{3,4}$ The overall strength evidence across studies was based on precepts outlined by the Grades of Recommendation Assessment, Development and Evaluation (GRADE) Working Group ${ }^{5}$ and recommendations made by the Agency for Healthcare Research and Quality (AHRQ). ${ }^{3,4}$

Details about methods can be found in the online supplementary material.

\section{Results}

- The search yielded 197 citations, 32 of which underwent full-text review. Only class of evidence (CoE) I or II (low or moderately low risk of bias) studies were considered for inclusion. Six studies met the inclusion criteria (-Fig. 1).

- A total of four unique studies of different populations comparing spinal manipulation or mobilization therapy of the cervical spine to physical therapy or exercise in patients with neck pain met the inclusion criteria. These studies were moderate-quality randomized controlled trials (RCT; CoE II). ${ }^{6-12}$ Three reports of the same study assessed different outcomes at different time points. ${ }^{9-11}$ In addition, two other reports of a same study evaluated outcomes at two different time points. ${ }^{7,8}$ One CoE II RCT met very few methodological criteria for high-quality study design, execution, and avoidance of bias. ${ }^{12}$ Additional details regarding the critical appraisal and study exclusion criteria are available in the online supplementary material.

- Table 1 describes the characteristics of included studies including subject and treatment characteristics. - Table 2

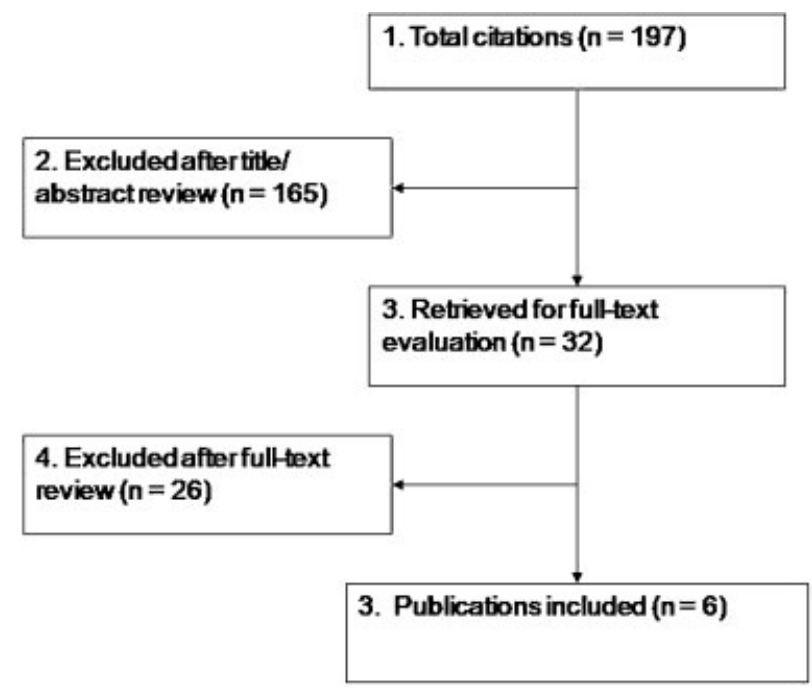

Fig. 1 Flowchart showing results of literature search. 


\begin{tabular}{|c|c|c|c|}
\hline 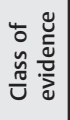 & $=$ & $=$ & $=$ \\
\hline 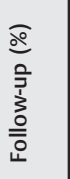 & 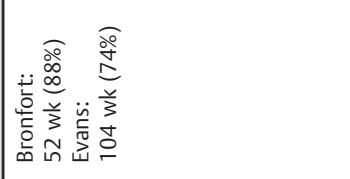 & 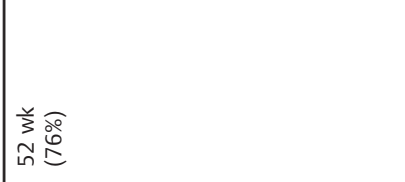 & 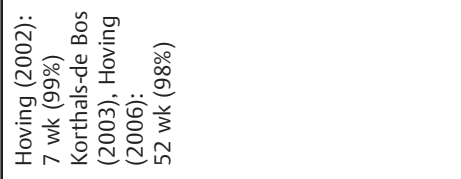 \\
\hline 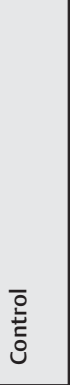 & 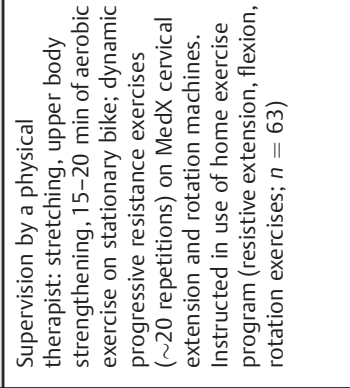 & 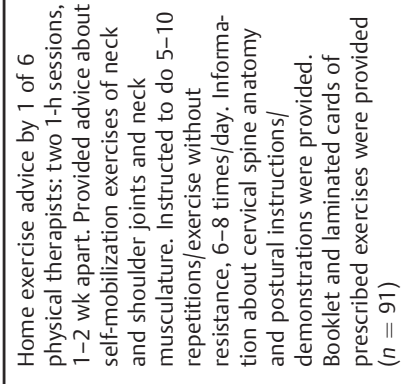 & 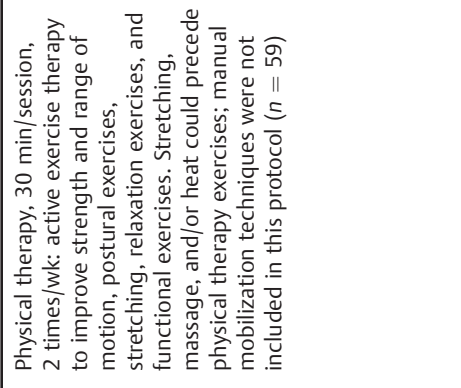 \\
\hline & 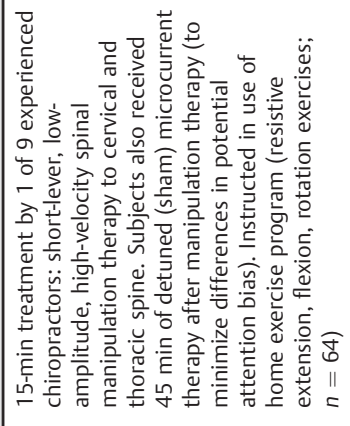 & 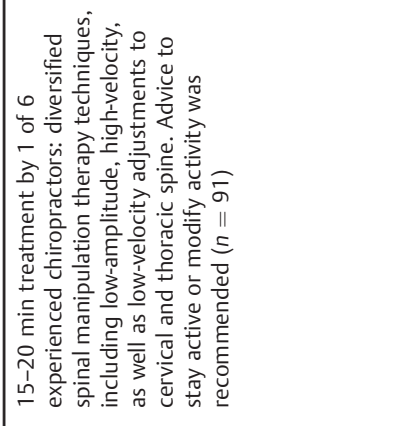 & 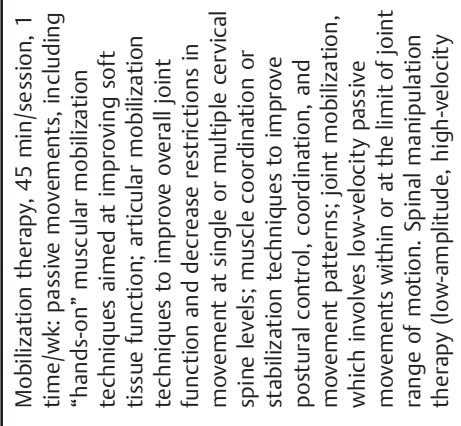 \\
\hline 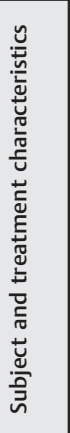 & 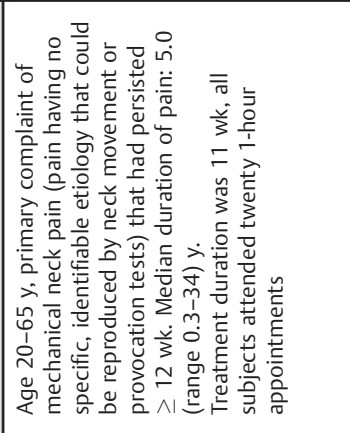 & 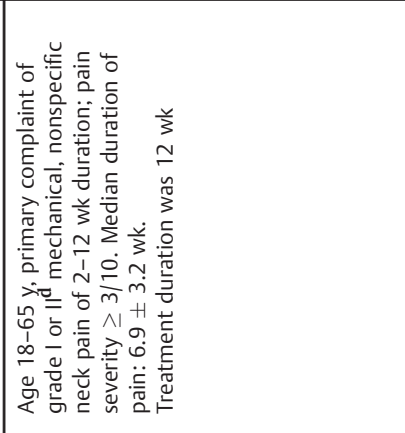 & 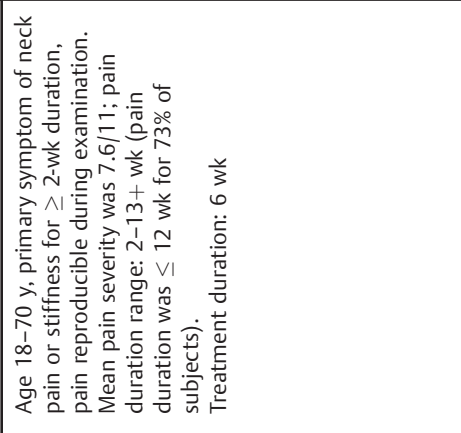 \\
\hline & 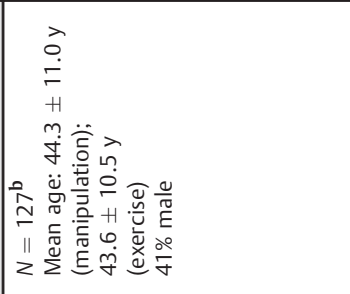 & 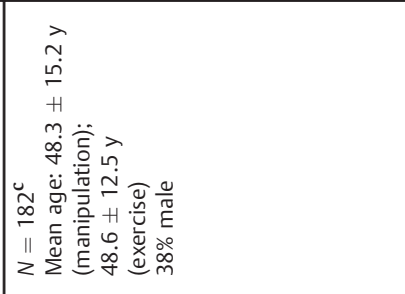 & 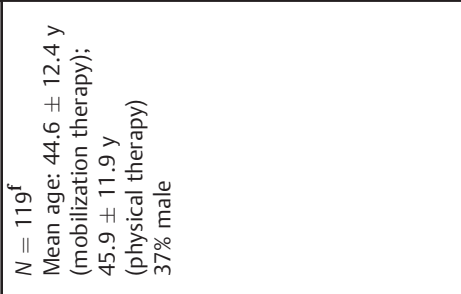 \\
\hline & 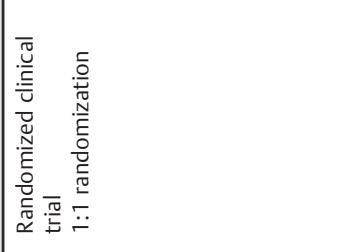 & 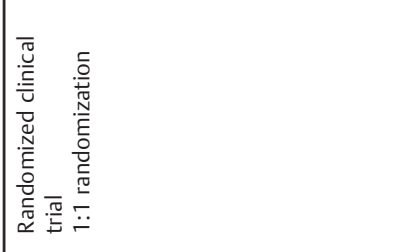 & 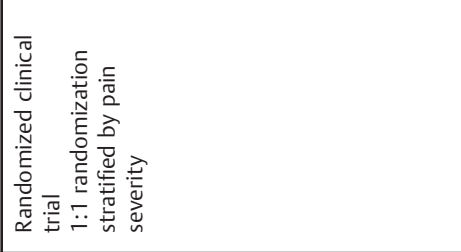 \\
\hline & 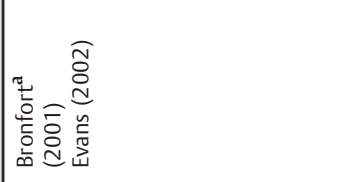 & 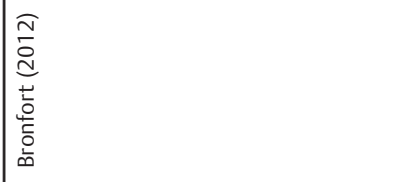 & 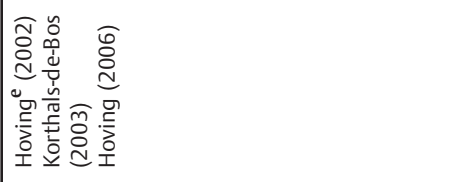 \\
\hline
\end{tabular}




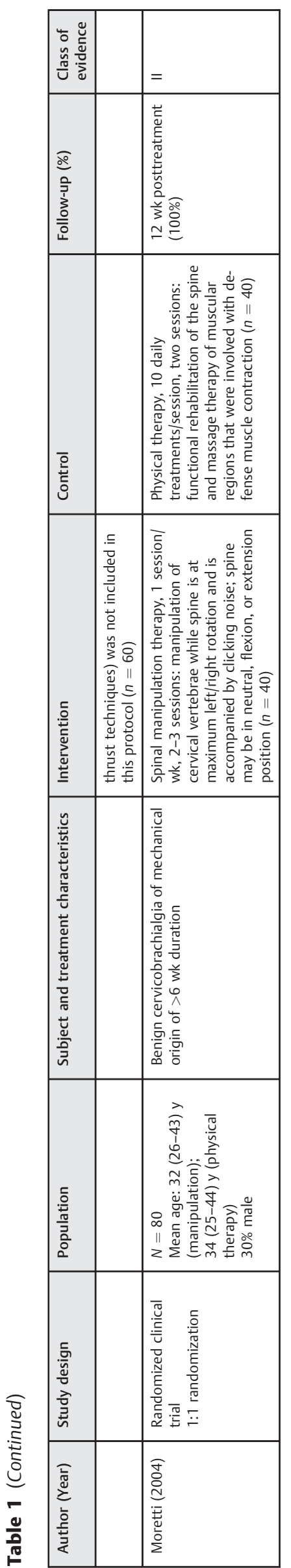

summarizes outcomes evaluated and effect-size estimates if reported in the studies of acute neck-pain patients, while - Table 3 summarizes outcomes evaluated and effect-size estimates if reported in the studies of patients reporting chronic neck pain.

\section{Acute Neck Pain (- Table 2)}

\section{Patient-Reported Outcomes}

- Pain: Pain improvement was assessed in all studies involving subjects with acute neck pain.

- One study comparing spinal manipulation therapy to home exercise instructions by a physical therapist found no differences in pain severity ( 0 to 10 scale, with 0 representing no pain and 10 representing pain "as bad as it could be") between groups at 12 and 52 weeks. $^{6}$

- Another study assessed average and most severe neck pain and pain "bothersomeness" (0 to 10 scales) in subjects who underwent mobilization therapy or physical therapy. There were no significant differences between groups at 7 weeks. However, at 52 weeks, the physical therapy group reported a significantly greater improvement in average neck pain from baseline levels compared with subjects who were treated with mobilization therapy $(p<0.05) .^{9-11}$

- A third study compared subjects who underwent mobilization therapy or physical therapy and found significantly lower levels of pain, rated with a 0 to 10 visual analogue scale (VAS), at 4 and 12 weeks after treatment in subjects who underwent mobilization therapy $(p<0.01) .^{12}$

- Disability: There were no significant differences in disability reported in manipulation therapy versus home exercise groups or in mobilization compared with physical therapy treatment groups at any time point in subjects with acute neck pain. 6,9-11

- Patient-reported treatment improvement:

○ There were no significant differences in self-reported treatment improvement (assessed using a 9-point scale, ranging from 1 [100\%improvement] to 5 [0\% improvement] to 9 [100\% worse], see - Table 3 ) in subjects who underwent spinal manipulation therapy vs. home exercise instructions at 12 or 52 weeks. ${ }^{6}$

- Subjects who underwent mobilization therapy reported a greater perceived recovery (assessed using a 6-point scale, ranging from "much worse" to "completely recovered") than those who received physical therapy at 7 weeks therapy $(p<0.05)$, though this improvement was no longer apparent at 52 weeks $(P=N S){ }^{9-11}$

\section{- Treatment satisfaction:}

- Subjects who received manipulation therapy reported a greater satisfaction with care (assessed using a 7-point scale, ranging from 1 [completely satisfied, could not be better] to 4 [neither satisfied nor dissatisfied] to 7 [completely dissatisfied, could not be 


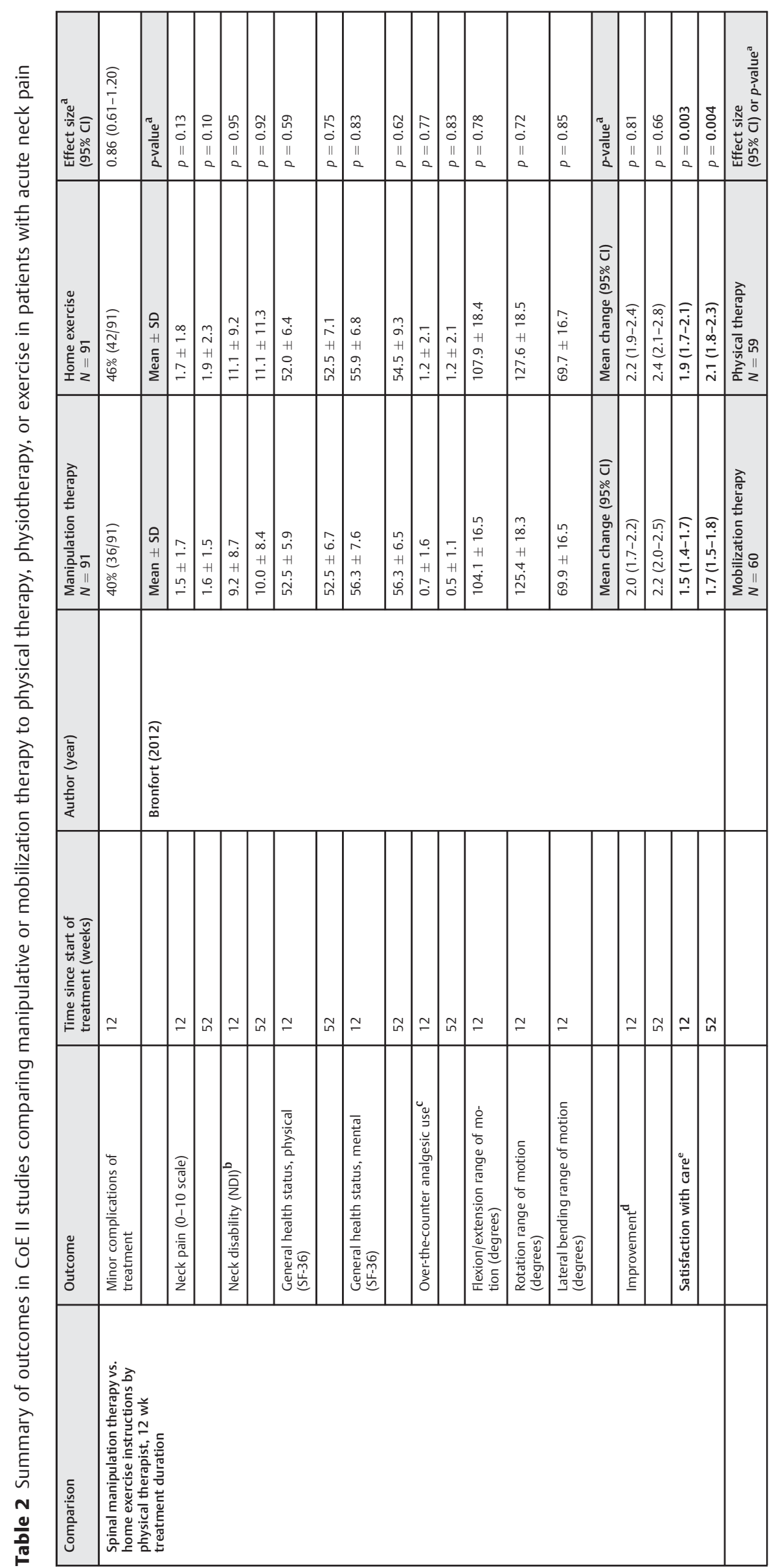




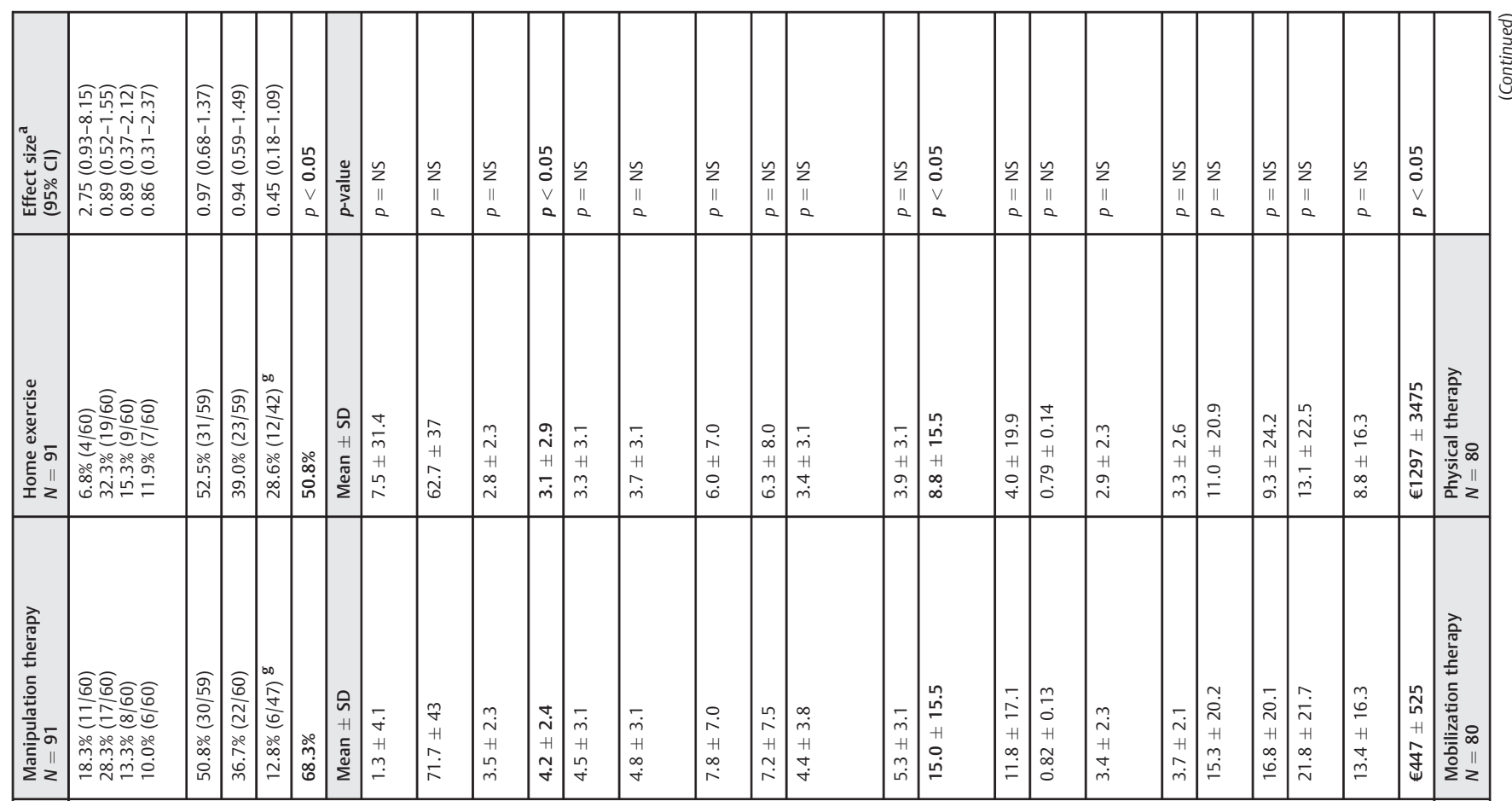

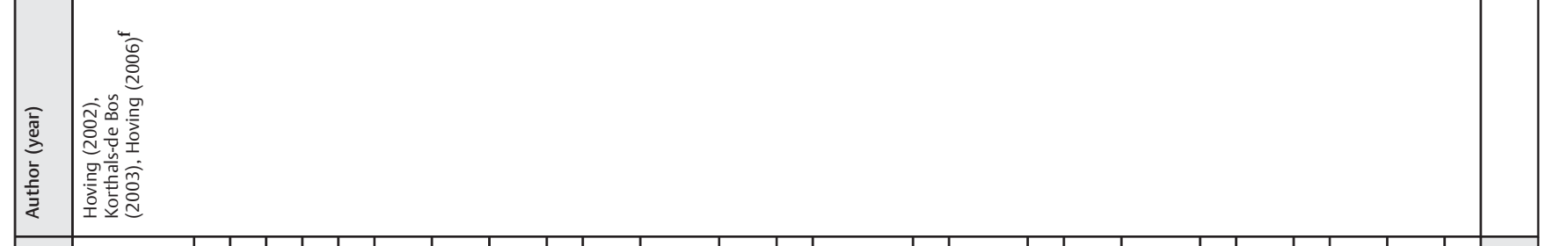

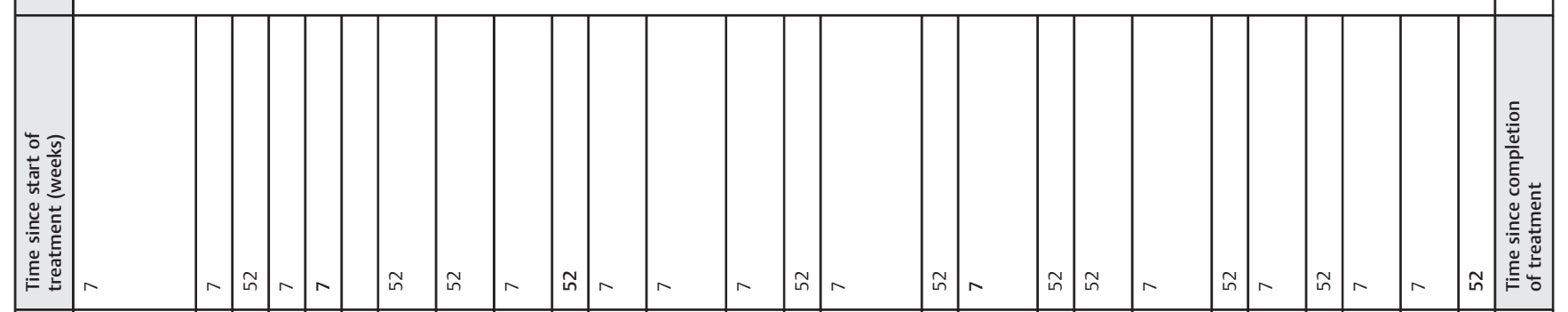

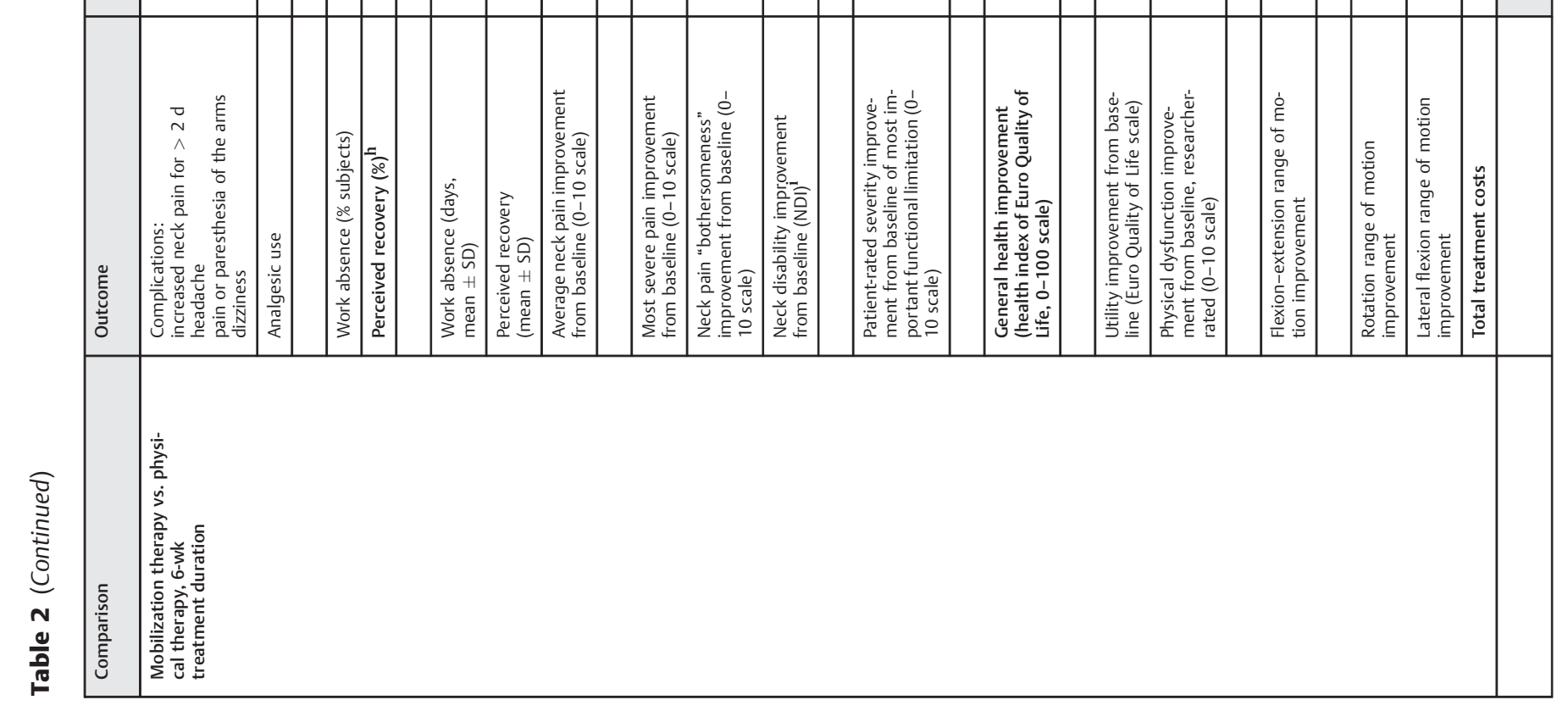


Schroeder et al.

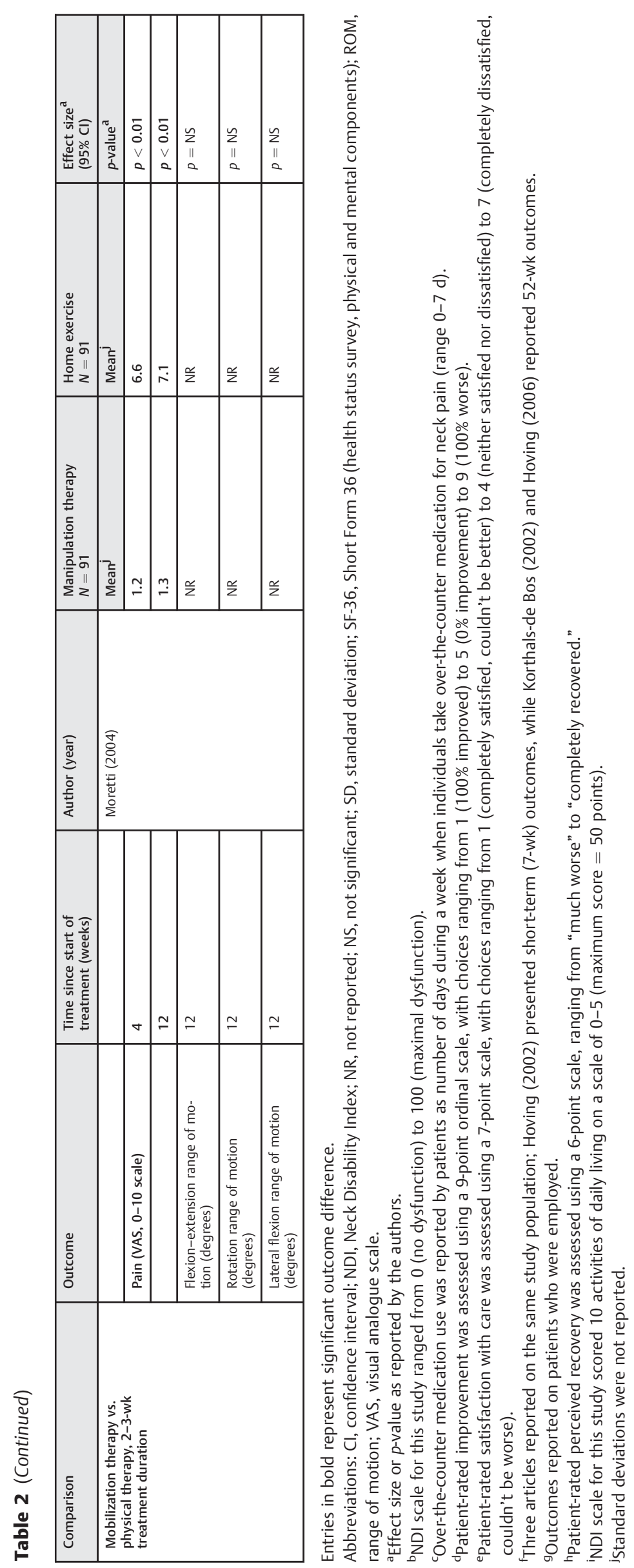



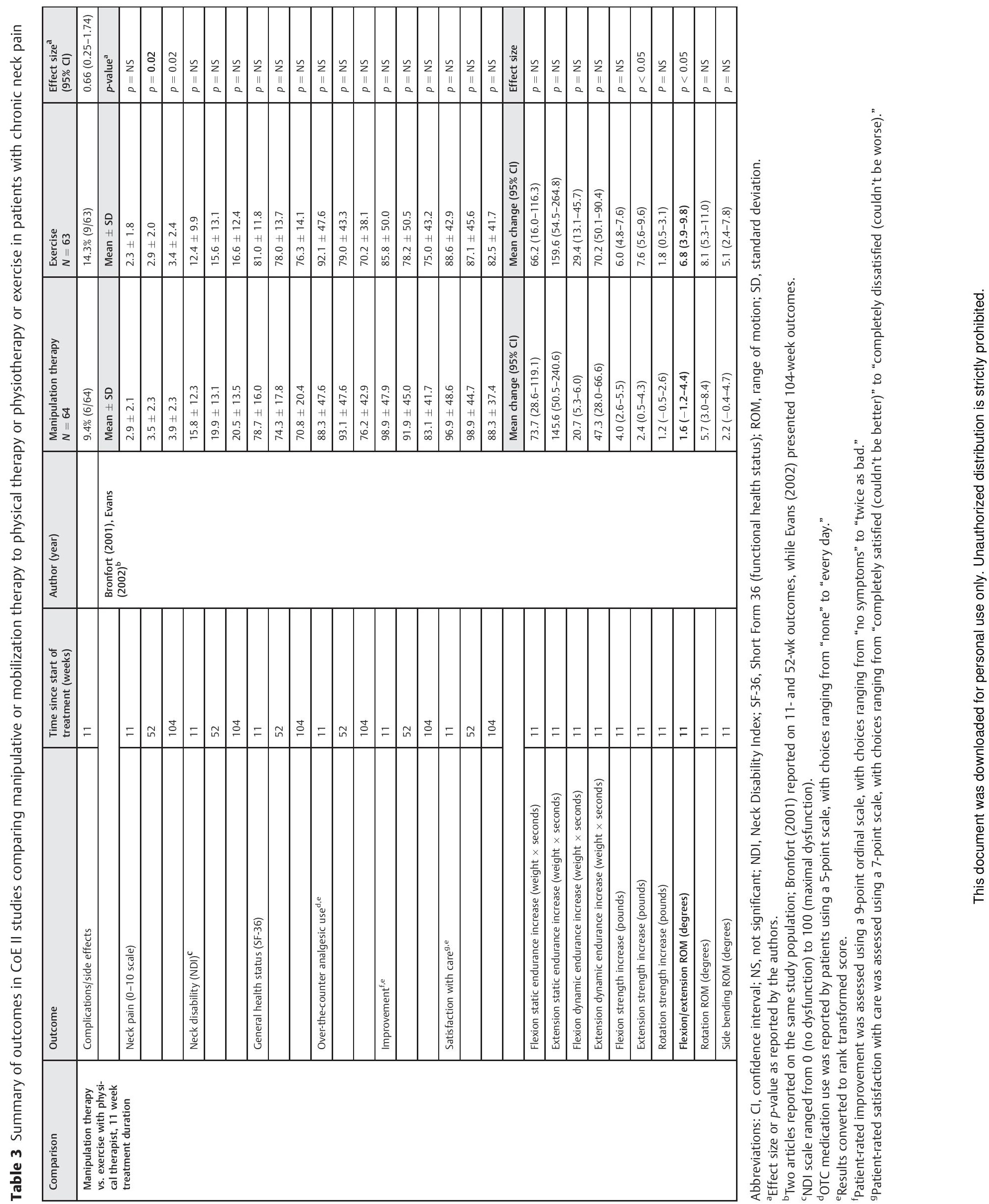
worse]) at 12 weeks $(p=0.003)$ and 52 weeks $(p=0.004)$ compared with those who underwent home exercise instructions. ${ }^{6}$

- Health status:

- No differences in physical or mental health status, measured with the SF-36, were found between spinal manipulation and home exercise instruction treatment groups at 12 or 52 weeks. ${ }^{6}$

- Subjects who underwent mobilization therapy compared with physical therapy reported a greater improvement in general health at 7 weeks, measured with the health index of the Euro Quality of Life scale, though this improvement was no longer apparent at 52 weeks. $^{9-11}$ No significant treatment differences between mobilization therapy and physical therapy treatment groups were found with utility improvement at 52 weeks, measured with the Euro Quality of Life scale. $^{9-11}$

\section{Functional Outcomes}

- Range of motion (ROM): There were no significant differences in flexion-extension ROM, rotation ROM, or lateral extension ROM between groups (manipulation therapy vs. home exercise, as well as mobilization vs. physical therapy) in studies involving acute neck pain subjects. ${ }^{6,9-12}$

\section{Other Outcomes}

- Complications: Reported complications were minor and were similar between manipulation therapy compared with home exercise and mobilization therapy compared with physical therapy treatment groups.,9-11

- Costs: One study assessed costs associated with care and found lower total medical utilization costs at 52 weeks after treatment associated with manipulation therapy compared with physical therapy $(p<0.05){ }^{11}$

- Other: In acute pain subjects, no significant differences in short- or long-term analgesic use were found between manipulation therapy versus home exercise, as well as mobilization therapy versus physical therapy treatment groups. ${ }^{6,9-11}$ Further, there were no significant differences in work absence, researcher-rated physical dysfunction, or patient-rated severity of the most important functional limitation in subjects who underwent mobilization therapy or physical therapy. ${ }^{9-11}$

\section{Chronic Neck Pain (-Table 3)}

\section{Patient-Reported Outcomes}

- Pain: In chronic pain subjects who received spinal manipulation therapy or intensive exercise with a physical therapist, no difference in pain intensity was found between the two groups at 11 weeks after treatment initiation, using a 0 to 10 rating scale with 0 representing no pain and 10 representing pain "as bad as it could be." However, at 52 and 104 weeks, significantly lower pain levels were reported in the exercise group $(p=0.02){ }^{7,8}$
- Disability: There were no significant differences in neck disability in subjects who underwent manipulation therapy or exercise treatment. ${ }^{7,8}$

- Patient-reported treatment improvement: No significant differences between manipulation therapy or exercise treatment groups were reported for self-rated improvement (rated with a 9-point scale ranging from 1 ["no symptoms"] to 9 ["twice as bad"]) at 11,52 , or 104 weeks. $^{7,8}$

- Patient-reported treatment satisfaction: In subjects who underwent spinal manipulation therapy or intensive exercise, no significant differences between treatment groups were reported for satisfaction with care (rated with a 7-point scale ranging from 1 ["completely satisfied"] to 7 ["completely dissatisfied"]; see - Table 4) at 11,52 , or 104 weeks. $^{7,8}$

- Health status: Health status was assessed with the SF-36, and no significant differences between manipulation therapies compared with exercise treatment groups were reported. ${ }^{7,8}$

\section{Functional Outcomes}

- Functional outcomes in chronic pain subjects were assessed at 11 weeks after initiation of treatment. There were no significant differences in flexion or extension endurance in subjects who received spinal manipulation therapy compared with exercise with a physical therapist. The exercise group experienced a greater improvement in extension strength, but not flexion or rotation strength, compared with the manipulation therapy group $(p<0.05)$. Further, the exercise group experienced a greater increase in flexion or extension range of motion, but not rotation or lateral flexion range of motion, compared with the manipulation therapy group $(p<0.05){ }^{7}$

\section{Other Outcomes}

- Complications: There were no significant differences in treatment complications reported when comparing subjects who underwent spine manipulation therapy to those who received exercise. ${ }^{7}$

- Other: No significant differences between treatment groups were reported for analgesic use at 11,52 , or 104 weeks. $^{7,8}$

\section{Clinical Guidelines}

Only one potentially relevant clinical guideline was identified.

The Bone and Joint Decade 2000-2010 Task Force on Neck Pain and Its Associated Disorders (Neck Pain Task Force) provided recommendations for assessment and treatment of patients with neck pain. ${ }^{13}$

- The Neck Pain Task Force recommends that people seeking primary care for neck pain should be triaged into four groups:

- Grade I: No signs of major pathology and no or little interference with daily activities 
Table 4 Strength of evidence summary

\begin{tabular}{|c|c|c|c|c|c|}
\hline Outcome & $\begin{array}{l}\text { Strength of } \\
\text { evidence }\end{array}$ & Conclusions and comments & Baseline & Downgrade & Upgrade \\
\hline \multicolumn{6}{|c|}{ Spinal manipulation therapy vs. exercise } \\
\hline Pain & $\begin{array}{l}\text { Acute: LOW } \\
\text { Chronic: LOW }\end{array}$ & $\begin{array}{l}\text { - Acute: No short- or long-term pain improvement } \\
\text { differences in manipulation therapy compared with } \\
\text { home exercise treatment groups were reported in one } \\
\text { study } \\
\text { - Chronic: No short-term pain improvement differences } \\
\text { were found in manipulation therapy vs. intense exercise } \\
\text { treatment groups, though a long-term pain } \\
\text { improvement was associated with exercise in one study }\end{array}$ & $\begin{array}{l}\text { Acute: } \mathrm{HIGH} \\
\text { Chronic: } \mathrm{HIGH}\end{array}$ & $\begin{array}{l}\text { YES }(2) \\
\text { consistency unknown, } \\
\text { imprecise } \\
\text { YES }(2) \\
\text { consistency unknown, } \\
\text { imprecise }\end{array}$ & $\begin{array}{l}\text { NO } \\
\text { NO }\end{array}$ \\
\hline Disability & $\begin{array}{l}\text { Acute: LOW } \\
\text { Chronic: LOW }\end{array}$ & $\begin{array}{l}\text { - Acute: No disability improvement was reported in } \\
\text { manipulation therapy compared with home exercise in } \\
\text { one study } \\
\text { - Chronic: No disability improvement was reported in } \\
\text { manipulation therapy compared with home exercise in } \\
\text { one study }\end{array}$ & $\begin{array}{l}\text { Acute: HIGH } \\
\text { Chronic: } \mathrm{HIGH}\end{array}$ & $\begin{array}{l}\text { YES (2) } \\
\text { consistency unknown, } \\
\text { imprecise } \\
\text { YES (2) } \\
\text { consistency unknown, } \\
\text { imprecise }\end{array}$ & $\begin{array}{l}\text { NO } \\
\text { NO }\end{array}$ \\
\hline Treatment improvement & $\begin{array}{l}\text { Acute: LOW } \\
\text { Chronic: LOW }\end{array}$ & $\begin{array}{l}\text { - Acute: No short- or long-term treatment improvement } \\
\text { between mobilization therapy and home exercise } \\
\text { groups were found in one study } \\
\text { - Chronic: No short- or long-term treatment } \\
\text { improvement differences between mobilization } \\
\text { therapy and home exercise groups were found in one } \\
\text { study }\end{array}$ & $\begin{array}{l}\text { Acute: } \mathrm{HIGH} \\
\text { Chronic: } \mathrm{HIGH}\end{array}$ & $\begin{array}{l}\text { YES }(2) \\
\text { consistency unknown, } \\
\text { imprecise } \\
\text { YES }(2) \\
\text { consistency unknown, } \\
\text { imprecise }\end{array}$ & $\begin{array}{l}\text { NO } \\
\text { NO }\end{array}$ \\
\hline Health status & $\begin{array}{l}\text { Acute: LOW } \\
\text { Chronic: LOW }\end{array}$ & $\begin{array}{l}\text { - Acute: No physical or mental health status change } \\
\text { between manipulation therapy and exercise groups } \\
\text { was found in one study } \\
\text { - Chronic: No health status improvement was reported in } \\
\text { one study }\end{array}$ & $\begin{array}{l}\text { Acute: } \mathrm{HIGH} \\
\text { Chronic: } \mathrm{HIGH}\end{array}$ & $\begin{array}{l}\text { YES }(2) \\
\text { consistency unknown, } \\
\text { imprecise } \\
\text { YES (2) } \\
\text { consistency unknown, } \\
\text { imprecise }\end{array}$ & $\begin{array}{l}\text { NO } \\
\text { NO }\end{array}$ \\
\hline Treatment satisfaction & $\begin{array}{l}\text { Acute: LOW } \\
\text { Chronic: LOW }\end{array}$ & $\begin{array}{l}\text { - Acute: Short- and long-term treatment satisfaction was } \\
\text { associated with manipulation therapy compared with } \\
\text { home exercise in one study } \\
\text { - Chronic: No differences in treatment satisfaction were } \\
\text { found between mobilization therapy and home } \\
\text { exercise groups in one study }\end{array}$ & $\begin{array}{l}\text { Acute: } \mathrm{HIGH} \\
\text { Chronic: } \mathrm{HIGH}\end{array}$ & $\begin{array}{l}\text { YES }(2) \\
\text { consistency unknown, } \\
\text { imprecise } \\
\text { YES (2) } \\
\text { consistency unknown, } \\
\text { imprecise }\end{array}$ & $\begin{array}{l}\text { NO } \\
\text { NO }\end{array}$ \\
\hline Functional improvement & $\begin{array}{l}\text { Acute: LOW } \\
\text { Chronic: LOW }\end{array}$ & $\begin{array}{l}\text { - Acute: No short-term functional improvement } \\
\text { differences in flexion/extension, rotation, or lateral } \\
\text { flexion range of motion were found in manipulation } \\
\text { therapy vs. home exercise groups in one study } \\
\text { - Chronic: Short-term improvement in extension } \\
\text { strength, but not flexion or rotation strength, and an } \\
\text { improvement in flexion/extension range of motion, but } \\
\text { not rotation or lateral flexion range of motion, were } \\
\text { found in subjects who underwent exercise compared } \\
\text { with mobilization therapy in one study }\end{array}$ & $\begin{array}{l}\text { Acute: } \mathrm{HIGH} \\
\text { Chronic: } \mathrm{HIGH}\end{array}$ & $\begin{array}{l}\text { YES }(2) \\
\text { consistency unknown, } \\
\text { imprecise } \\
\text { YES (2) } \\
\text { consistency unknown, } \\
\text { imprecise }\end{array}$ & $\begin{array}{l}\text { NO } \\
\text { NO }\end{array}$ \\
\hline \multicolumn{6}{|c|}{ Mobilization therapy vs. physical therapy } \\
\hline Pain & $\begin{array}{l}\text { Acute: LOW } \\
\text { Acute: LOW }\end{array}$ & $\begin{array}{l}\text { - Acute: Short-term pain improvement was associated } \\
\text { with mobilization therapy, compared with physical } \\
\text { therapy, in one study, and there were no differences } \\
\text { between groups in another study } \\
\text { - Acute: long-term pain improvement was associated } \\
\text { with physical therapy, compared with mobilization } \\
\text { therapy, in one study and was not reported in another } \\
\text { study }\end{array}$ & $\begin{array}{l}\text { Acute: } \mathrm{HIGH} \\
\text { Acute: } \mathrm{HIGH}\end{array}$ & $\begin{array}{l}\text { YES (2) } \\
\text { inconsistent, imprecise } \\
\text { YES (2) } \\
\text { consistency unknown, } \\
\text { imprecise }\end{array}$ & NO \\
\hline Disability & Acute: LOW & $\begin{array}{l}\text { - Acute: No disability improvement was reported in } \\
\text { mobilization therapy compared with physical therapy } \\
\text { in one study }\end{array}$ & Acute: HIGH & $\begin{array}{l}\text { YES (2) } \\
\text { consistency unknown, } \\
\text { imprecise }\end{array}$ & NO \\
\hline Treatment improvement & Acute: LOW & $\begin{array}{l}\text { - Acute: Short-term perceived treatment recovery was } \\
\text { associated with mobilization therapy, compared with } \\
\text { physical therapy, in one study }\end{array}$ & Acute: HIGH & $\begin{array}{l}\text { YES }(2) \\
\text { consistency unknown, } \\
\text { imprecise }\end{array}$ & NO \\
\hline Health status & Acute: LOW & $\begin{array}{l}\text { - Acute: Short-term health status improvement was } \\
\text { associated with mobilization therapy, compared with } \\
\text { physical therapy, in one study. No long-term utility } \\
\text { (quality of life) improvement between groups was } \\
\text { found in another study }\end{array}$ & Acute: $\mathrm{HIGH}$ & $\begin{array}{l}\text { YES (2) } \\
\text { consistency unknown, } \\
\text { imprecise }\end{array}$ & NO \\
\hline Functional improvement & $\begin{array}{l}\text { Acute: MODERATE } \\
\text { Acute: LOW }\end{array}$ & $\begin{array}{l}\text { - Acute: No short-term functional improvement } \\
\text { differences in flexion/extension, rotation, or lateral } \\
\text { flexion range of motion were found in manipulation } \\
\text { therapy vs. home exercise groups in two studies } \\
\text { - Acute: No long-term functional improvement } \\
\text { differences in flexion/extension, rotation, or lateral } \\
\text { flexion range of motion were found in manipulation } \\
\text { therapy vs. home exercise groups in one study }\end{array}$ & $\begin{array}{l}\text { Acute: } \mathrm{HIGH} \\
\text { Acute: } \mathrm{HIGH}\end{array}$ & $\begin{array}{l}\text { YES (1) } \\
\text { imprecise } \\
\text { YES ( } 2) \\
\text { consistency unknown, } \\
\text { imprecise }\end{array}$ & $\begin{array}{l}\text { NO } \\
\text { NO }\end{array}$ \\
\hline
\end{tabular}


○ Grade II: No signs of major pathology, but interference with daily activities

- Grade III: Neurologic signs of nerve compression

- Grade IV: Signs of major pathology

- Diagnostic testing is not indicated in the initial assessment of grade I or II neck pain. People with suspected grade III neck pain might require elective investigation. People with suspected grade IV neck pain require immediate investigation.

- Exercises and mobilization have been shown to provide some degree of short-term relief of grade I or II neck pain after a motor vehicle collision.

- Exercises, mobilization, manipulation, analgesics, acupuncture, and low-level laser have been shown to provide some degree of short-term relief of grade I or II neck pain without trauma.

- Those with confirmed grade III and severe persistent radicular symptoms might benefit from corticosteroid injections or surgery. Those with confirmed grade IV neck pain require management specific to the diagnosed pathology.

\section{Evidence Summary}

In patients who underwent manipulation therapy compared with exercise, the overall strength of evidence was low for treatment of both acute and chronic pain; that is, we have low confidence that the evidence reflects the true effect of differences in outcomes between treatments, and future research is likely to change the confidence in the estimate of effect and is likely to change the estimate ( - Table 4 ). For comparisons of mobilization therapy versus physical therapy, the overall strength of evidence is low for all outcomes with the exception of short-term functional improvement, which was considered moderate, meaning that we have moderate confidence that the evidence reflects the true effect, and further research may change our confidence in the estimate of effect and may change the estimate ( - Table 4 ). No studies were performed in patients with chronic pain comparing these treatments.

\section{Discussion}

- The review highlights the fact that manipulation or mobilization therapy has limited benefit when compared with physical therapy or exercise in both acute and chronic neck-pain patients. Consequently, providers often choose multimodal therapy for patients with neck pain.

- Conclusions from this systematic review are limited by the variability in outcomes measured, failure to use standardized outcome measures, and studies may have been insufficiently powered to detect treatment differences. Additional limitations include variability in case definitions across studies and inconsistency in the length of follow-up of subjects.

- The data available suggest that there are minimal shortand long-term treatment differences in pain, disability, patient-reported treatment improvement, treatment satisfaction, and health status, as well as functional improvement, when comparing manipulation or mobiliza- tion therapy to physical therapy or exercise in patients with neck pain. Future research should be aimed at standardizing interventions and treatment outcomes to reduce the variability of research findings.

\section{Funding}

Analytic support for this work was provided by Spectrum Research, Inc. with funding from AOSpine.

\section{Conflict of Interest \\ None}

\section{References}

1 Côté P, Cassidy JD, Carroll L. The Saskatchewan Health and Back Pain Survey. The prevalence of neck pain and related disability in Saskatchewan adults. Spine (Phila Pa 1976) 1998;23(15):1689-1698

2 Wright JG, Swiontkowski MF, Heckman JD. Introducing levels of evidence to the journal. J Bone Joint Surg Am 2003;85-A(1):1-3

3 West S, King V, Carey TS, et al. Systems to Rate the Strength of Scientific Evidence. Evidence Report/Technology Assessment No. 47 (prepared by the Research Triangle Institute-University of North Carolina Evidence-Based Practice Center, Contract No. 290-97-0011). Rockville, MD: Agency for Healthcare Research and Quality; 2002

4 Methods Guide for Effectiveness and Comparative Effectiveness Reviews. AHRQ Publication No. 10(12)-EHC063-EF. Rockville, MD; April 2012. Available at: www.effectivehealthcare.ahrq.gov

5 Atkins D, Best D, Briss PA, et al; GRADE Working Group. Grading quality of evidence and strength of recommendations. BMJ 2004;328(7454):1490

6 Bronfort G, Evans R, Anderson AV, Svendsen KH, Bracha Y, Grimm RH. Spinal manipulation, medication, or home exercise with advice for acute and subacute neck pain: a randomized trial. Ann Intern Med 2012;156(1, Pt 1):1-10

7 Bronfort G, Evans R, Nelson B, Aker PD, Goldsmith CH, Vernon H. A randomized clinical trial of exercise and spinal manipulation for patients with chronic neck pain. Spine (Phila Pa 1976) 2001;26 (7):788-797, discussion 798-799

8 Evans R, Bronfort G, Nelson B, Goldsmith CH. Two-year follow-up of a randomized clinical trial of spinal manipulation and two types of exercise for patients with chronic neck pain. Spine (Phila Pa 1976) 2002;27(21):2383-2389

9 Hoving JL, de Vet HC, Koes BW, et al. Manual therapy, physical therapy, or continued care by the general practitioner for patients with neck pain: long-term results from a pragmatic randomized clinical trial. Clin J Pain 2006;22(4):370-377

10 Hoving JL, Koes BW, de Vet HC, et al. Manual therapy, physical therapy, or continued care by a general practitioner for patients with neck pain. A randomized, controlled trial. Ann Intern Med 2002;136(10):713-722

11 Korthals-de Bos IB, Hoving JL, van Tulder MW, et al. Cost effectiveness of physiotherapy, manual therapy, and general practitioner care for neck pain: economic evaluation alongside a randomised controlled trial. BMJ 2003;326(7395):911

12 Moretti B, Vetro A, Garofalo R, et al. Manipulative therapy in the treatment of benign cervicobrachialgia of mechanical origin. Chir Organi Mov 2004;89(1):81-86

13 Guzman J, Haldeman S, Carroll LJ, et al; Bone and Joint Decade 2000-2010 Task Force on Neck Pain and Its Associated Disorders. Clinical practice implications of the Bone and Joint Decade 20002010 Task Force on Neck Pain and Its Associated Disorders: from concepts and findings to recommendations. Spine (Phila Pa 1976) 2008;33(4, Suppl):S199-S213 


\section{Editorial Perspective}

Understandably, nonoperative care of spine-related pain remains the preferred primary treatment approach for all but the most serious spinal conditions. When back symptoms persist beyond an acute phase of several days, several nonoperative options are used, including activity modifications, pharmacologic, educational, physical, exercise, and manipulative ("hands-on") modalities. Sadly, attempts at scientific assessment of the outcomes and efficacies of nonoperative treatment of refractory back-related pain-be it in the neck or the low back-remain one of the most frustrating but also expensive aspects of spine care. In a systematic review of exercise, acupuncture, and spinal manipulation, Standaert et al found no advantage of one modality over another with a low level of evidence. ${ }^{1}$ There was insufficient evidence to allow for the determination of cost-effectiveness and general lack of validation for any such therapy to be performed beyond 8 weeks without thorough reevaluation. In a systematic review of pharmacologic management of chronic low back pain, opioids were found to be not recommended over nonsteroidal anti-inflammatory drugs due to a significant rate of side effects. ${ }^{2}$ For surgical practices, there are emerging methods to assess the impact of procedures on patient wellbeing and cost-effectiveness as expressed in Quality Adjusted Life Years (QUALYS), but so far these methodologies have not been applied to nonoperative care. ${ }^{3,4}$

Our reviewers universally welcomed the initiative of the authors of this systematic review. They expressed worries about the influence and variability of patient education provided. The authors complied with this concern by adjustment of inclusion and exclusion criteria and excluding pharmacotherapy. Patient education is felt to be an essential adjuvant to all care options, yet its effect on patient outcomes remains unclear. $^{5}$ The other concerns are much harder to address: the variability of manual and physical therapies applied, the inconsistent practitioner and patient interactive responsiveness (including a placebo effect), and the difficulty in establishing a differentiation of relatively harmless selflimiting discomfort to a more chronic pain state. Overall, the findings of this review by Schroeder et al were consistent with the findings of other systematic reviews, such as the Standaert et al study on low back pain. There is no discernible advantage of one modality over another, and the overall effectiveness of these interventions remains elusive. While most patients seem to get better over time, there remains a troubling group of patients who fail to respond and develop chronic pain. This valuable review hopefully strengthens the impetus for a more formal study on the role of nonoperative care, its preferred implementation strategies, and early recognition of patients who fail to respond to usual nonoperative care.

\section{References}

1 Standaert CJ, Friedly J, Erwin MW, et al. Comparative effectiveness of exercise, acupuncture, and spinal manipulation for low back pain. Spine (Phila Pa 1976) 2011;36(21 Suppl):S120-S130

2 White AP, Arnold PM, Norvell DC, Ecker E, Fehlings MG. Pharmacologic management of chronic low back pain: synthesis of the evidence. Spine (Phila Pa 1976) 2011;36(21 Suppl):S131-S143

3 Adogwa O, Parker SL, Shau DN, et al. Cost per quality-adjusted life year gained of revision neural decompression and instrumented fusion for same-level recurrent lumbar stenosis: defining the value of surgical intervention. J Neurosurg Spine 2012;16(2):135-140

4 Henrikson NB, Skelly AC. Economic studies part I: basics and terms. Evid Based Spine Care J 2012;3(4):7-11

5 Cherkin DC, Deyo RA, Street JH, Hunt M, Barlow W. Pitfalls of patient education. Limited success of a program for back pain in primary care. Spine (Phila Pa 1976) 1996;21(3):345-355 